\title{
Assessing the Impact of Caring for a Person with Schizophrenia: Development of the Schizophrenia Caregiver Questionnaire
}

\author{
Adam Gater - Diana Rofail - Chris Marshall • \\ Chloe Tolley • Linda Abetz-Webb • Steven H. Zarit • \\ Carmen Galani Berardo
}

Published online: 14 February 2015

(c) The Author(s) 2015. This article is published with open access at Springerlink.com

\begin{abstract}
Background The responsibilities of caring for a person with schizophrenia may significantly impact informal caregivers' lives. The Zarit Burden Interview (ZBI) was originally developed to assess burden among caregivers of people with Alzheimer's disease.

Objective This research was conducted to inform the development of a revised version of the ZBI, relevant to caregivers of people with schizophrenia.

Methods Based on published qualitative research, the questionnaire was reviewed and modified in accordance with industry-standard guidelines. The resulting questionnaire [the Schizophrenia Caregiver Questionnaire (SCQ)] was then completed by 19 caregivers during cognitive debriefing interviews to assess understanding, relevance and comprehensiveness.

Results Review of the ZBI resulted in a number of operational changes to improve face validity and potential sensitivity. Further questions were added based on key concepts identified in existing literature and minor phrasing alterations
\end{abstract}

A. Gater $(\bowtie) \cdot$ C. Marshall · C. Tolley $\cdot$ L. Abetz-Webb

Adelphi Values Ltd, Adelphi Mill, Bollington,

Cheshire SK10 5JB, UK

e-mail: adam.gater@adelphivalues.com

D. Rofail

Roche Products Ltd, Hexagon Place, 6 Falcon Way, Welwyn

Garden City, Hertfordshire, UK

S. H. Zarit

Department of Human Development and Family Studies,

College of Health and Human Development, The Pennsylvania

State University, University Park, PA, USA

C. G. Berardo

F. Hoffmann La-Roche Ltd, Grenzacherstrasse 124, Basel,

Switzerland were made to improve content validity. Findings from caregiver interviews supported the content validity of the SCQ. Conclusion The SCQ provides a comprehensive view of caregivers' subjective experiences of caregiving and demonstrated strong face and content validity. The questionnaire will be important in both clinical assessment and evaluating the efficacy of interventions designed to reduce or alleviate caregiver burden. Future research will seek to establish the psychometric validity of the questionnaire.

\section{Key Points for Decision Makers}

The Zarit Burden Interview (ZBI) is a widely used measure of caregiver burden; however, it has not been validated for use in caregivers of people with schizophrenia.

Following a review of the content of the ZBI and informed by qualitative interviews with caregivers of people with schizophrenia, the ZBI has been modified to develop a new disease-specific measure: the Schizophrenia Caregiver Questionnaire (SCQ).

The SCQ was shown to be comprehensive and relevant to caregivers of people with schizophrenia and has strong face validity.

Future work is ongoing to determine the reliability and validity of the instrument in this population.

\section{Background}

Over the past 50 years there has been transition in care provision for schizophrenia patients from formal hospitalbased healthcare systems to outpatient and community 
services. It is estimated that $50-90 \%$ of people with chronic psychiatric illness live with their families or friends $[1,2]$. Informal caregivers (defined as "a person who has significant responsibility for managing the well-being of a person diagnosed with schizophrenia in an unpaid capacity" [3]) therefore provide an important service by reducing the need for formal care and the burden upon healthcare systems [4].

While providing informal care for a person with schizophrenia can be a rewarding experience, fulfilment of this role can have a significant impact upon the life of an informal caregiver, including interpersonal relationships, ability to fulfil other roles and commitments (e.g. work), and financial situation [5, 6]. In addition, high levels of perceived burden among caregivers can lead to increased physical and psychological health problems, which in turn can have considerable consequences on healthcare systems and wider society. Not only do the healthcare needs of overburdened caregivers incur costs, but a loss of productivity due to terminated employment and time off work and an increasing reliance on formal, paid assistance result in substantial costs to society [7, 8]. In the UK in 2007 , for instance, it was estimated that $4.8 \%$ of caregivers of people with schizophrenia had terminated employment and $15.5 \%$ took a mean of 12.5 days off work per year as a result of their caregiving role, which translated into a mean economic loss of $£ 517$ per caregiver each year [9].

Health technology assessments in many countries, as well as payers and prescribers, now recognise the value of evidence demonstrating alleviation of the impact of providing informal care for someone with a medical condition for facilitating decision making. In order to monitor the subjective impact on caregivers, however, there is a need for an accurate and reliable measure which assesses the impact perceived by caregivers as opposed to the observable impact on their lives. This can only be reported by caregivers themselves.

The Zarit Burden Interview (ZBI) is a 22-item questionnaire developed to assess the level of subjective burden experienced by the principal caregivers of people with dementia and people with disabilities [10]. The ZBI, which was developed in 1980, is arguably the most widely used measure of caregiver burden. The instrument has been adapted for use in a number of languages [11-16] and has been used extensively in clinical studies and published research among caregivers of people with a variety of physical and mental disorders, including schizophrenia [17-19]. Despite this, however, the relevance and meaningfulness of the ZBI for use in schizophrenia is still unknown. Similarly, the validity of the ZBI for monitoring caregiver burden in clinical research or longitudinal studies in schizophrenia has also not been evaluated.
The aims of the present study were to review evidence supporting the validity of the ZBI for assessment of the impact of caring for a person with schizophrenia in accordance with best practice guidelines for the development and evaluation of self-report measures (e.g. US Food and Drug Administration Guidance for Industry-Patient-Reported Outcomes Measures: Use in Medical Product Development to Support Labeling Claims) [20]; inform modifications to the ZBI; and explore the relevance and understanding of the resulting questionnaire [the Schizophrenia Caregiver Questionnaire (SCQ)] during qualitative cognitive debriefing interviews with caregivers of people with schizophrenia.

\section{Methods}

\subsection{Phase 1: Zarit Burden Interview (ZBI) Endpoint} Review

\subsubsection{Literature Searches}

Targeted literature searches were conducted in MEDLINE, EMBASE and PsycInfo, using a combination of keywords (Table 1). The two main objectives of the literature review were firstly to identify articles outlining the experience of caring for a person with schizophrenia based on qualitative research and secondly to identify articles concerning the development and validation of the ZBI or articles detailing the use of the questionnaire in schizophrenia studies. Articles which met pre-specified inclusion and exclusion criteria were selected for review (Table 1). Searches returned 203 qualitative articles and 16 articles relating to the ZBI. A total of 19 qualitative articles [21-44], 16 articles concerning the development of the ZBI [11-16, 19, 45-53] and eight studies detailing the use of the ZBI in schizophrenia [17, 18, 54-59] met the inclusion criteria and were selected for review.

\subsubsection{ZBI Review Criteria}

Key criteria from best practice guidelines relating to the content and face validity of self-report questionnaires that were considered during the review of the ZBI are defined in Table $2[20,60]$.

\subsubsection{Modifications to the ZBI to Form the Schizophrenia Caregiver Questionnaire (SCQ)}

Based on findings from the literature, review of the ZBI and author experience in the development of self-report measures [61-70], changes were made to the ZBI to address concerns regarding relevance and sensitivity of the 
Table 1 Search strategy for the Zarit Burden Interview ZBI endpoint review

\begin{tabular}{|c|c|}
\hline $\begin{array}{l}\text { Qualitative literature review key } \\
\text { terms }\end{array}$ & $\begin{array}{l}\text { ("Schizophrenia" OR "Schizoaffective") AND ("Caregiver" OR "Carer" OR "Care provider" OR } \\
\text { "Responsible person" OR "Spouse" OR "Parent" OR "Sibling" OR "Family" OR "Friends" OR } \\
\text { "Daughter" OR "Son" OR "Child\$" OR "Healthcare professional" OR "Doctor" OR "Clinician" OR } \\
\text { "Nurse" OR "Mental Health Nurse" OR "Mental Health Professional" OR "Nurse Practitioner") AND } \\
\text { ("Qualitative" or "IPA" or "Interpretive phenomenological analysis" or "Thematic analysis" or } \\
\text { "Grounded theory" or "Content analysis" or "Discourse" OR "Interviews" OR "Focus Groups") AND } \\
\text { ("Lived experience" or "Quality of life" OR "Burden" OR "Impact") }\end{array}$ \\
\hline \multirow{7}{*}{$\begin{array}{l}\text { Qualitative literature review } \\
\text { inclusion criteria }\end{array}$} & Include: \\
\hline & Journal article (excludes conferences, dissertations, books or chapters) \\
\hline & Article focuses exclusively on burden among caregivers of schizophrenia patients \\
\hline & Article reports use of qualitative techniques of investigation \\
\hline & $\begin{array}{l}\text { Article focuses on burden among caregivers of patients with mental disorders (including reference to } \\
\text { schizophrenia) }\end{array}$ \\
\hline & Exclude: \\
\hline & Relevant search terms are mentioned but are not the main focus of article \\
\hline ZBI review key terms & ("Schizophrenia" OR "Schizoaffective") AND ("Zarit") \\
\hline \multirow[t]{5}{*}{ ZBI review inclusion } & Include: \\
\hline & Journal article (excludes conferences, dissertations, books or chapters) \\
\hline & $\begin{array}{l}\text { Article refers explicitly to the evaluation of the psychometric properties of the original ZBI or alternate } \\
\text { language versions }\end{array}$ \\
\hline & Exclude: \\
\hline & Relevant search terms are mentioned but are not the main focus of article \\
\hline
\end{tabular}
Searches were conducted in November 2011 and were limited to English articles that concerned humans and contained keywords in the title or abstract

ZBI Zarit Burden Interview

Table 2 Endpoint review criteria assessed

\begin{tabular}{ll}
\hline Evidence & Issues for consideration \\
\hline Content validity & Does the questionnaire adequately capture all concepts that are important to patients and in a way that is easily understood and \\
interpreted consistently by patients? \\
Level of participant involvement in development of questionnaire? \\
Has pilot test/cognitive debriefing been conducted? \\
Confirmation of conceptual model? \\
Evidence of conceptual saturation? \\
Does the questionnaire appear to measure what it intends to measure in a manner appropriate for the context of use? \\
Questionnaire wording: \\
Are questions, response scales and instructions worded in a manner that is clear and will be consistently interpreted by \\
patients? \\
Recall period: \\
Appropriate recall period? (Dependent on variability, duration, frequency and intensity of the concept measured, \\
characteristics of the disease/condition) \\
Response scales and scoring: \\
Response scales represent similar intervals and do not bias the direction of responses? \\
Response options are appropriate for the intended population? \\
Do the scores represent a single concept?
\end{tabular}


questionnaire in this population. All changes were based on consensus decision among all authors. These changes are further described in the Results section.

\subsubsection{Development of Supplementary Measures to Understand Caregiver Impact: Caregiver Global Impression Scales}

To aid the interpretation of SCQ scores over time and repeated assessments, a series of Caregiver Global Impression $(\mathrm{CaGI})$ scales were also developed and tested among caregivers (Fig. 1). These scales are similar to Clinical Global Impression (CGI) scales commonly used in psychiatry research [71] but were developed to be suitable for completion by caregivers of people with schizophrenia. Three scales were developed to assess caregivers' perception of the severity of the person with schizophrenia's symptoms over the past 4 weeks ["Please rate the severity of his/her symptoms during the past 4 weeks" scored from symptoms (1) to very severe symptoms (6)]; change in the person with schizophrenia's symptoms since the beginning of the study ["Overall, how have his/her symptoms changed (if at all) since the beginning of the study (before starting treatment)?" scored from "very much improved" (1) to "very much worse" (7)]; and change in the experience of caring since the beginning of the study ["Overall, how much have your experiences of caring for a person with schizophrenia changed (if at all) since the beginning of the study (before starting treatment)?" scored from "very much improved" (1) to "very much worse" (7)].

\subsection{Phase 2: Cognitive Debriefing Interviews Among Caregivers of People with Schizophrenia}

The first step in the development or modification of selfreport questionnaires is to confirm content validity in the target population. In accordance, face-to-face, semi-structured, cognitive debriefing interviews were performed with 19 US English-speaking caregivers of people with schizophrenia. In a cognitive debriefing interview, respondents are asked to complete a questionnaire whilst talking through their thought processes (i.e. thinking out loud); the interviewer then questions the respondent on the relevance of items and their understanding of the questionnaire. Respondents' answers during cognitive debriefing of the SCQ and CaGI scales were reviewed to ensure that: (1) the content of the instruments captures the most important aspects of the concept(s) relevant to caregivers; and (2) caregivers understand how to complete the instruments, how to reference the correct recall periods, the meaning of the items, how to use the response scales, and any other features of the instruments that may influence caregiver responses in the intended mode of administration [72].

\subsubsection{Caregiver Recruitment}

No definitive guidelines exist regarding the recommended sample sizes for qualitative studies; however, past studies suggest that sample sizes of approximately 12 participants are sufficient for determination of issues of importance to a particular population and for confirmation of user understanding of self-report measures via cognitive debriefing [73, 74]. Evidence suggests the number of interviews is less important than the quality of interviews, with completeness of elicited information strongly influencing sample size [20].

In order to avoid geographical bias, participants were recruited from three sites in the USA (central, eastern and southern states). Caregivers of people with schizophrenia who met predefined eligibility criteria were referred to the study by private physicians. To be eligible for participation, caregivers had to be aged at least 18 years of age and currently providing care for at least $4 \mathrm{~h}$ per week to a person with a Diagnostic and Statistical Manual of Mental Disorders, 4th Edition, Text Revision (DSM-IV-TR) [91] diagnosis of schizophrenia who was currently receiving a marketed atypical or typical antipsychotic, and was defined by their physician on a CGI scale as being at least moderately ill.

A number of external factors were considered in developing recruitment quotas for the current study. These included care recipient subtype [75-77] and severity of schizophrenia [78-81]. The ethnicity [82], sex [78, 83], age [34], education [84] and relationship of the caregiver to person with schizophrenia [85] were also considered as existing research had indicated that these variables may influence the type and extent of the impact of caring for a person with schizophrenia.

\subsubsection{Cognitive Debriefing Interview Procedure}

Interviews were conducted by an experienced qualitative interviewer using a semi-structured interview guide. The SCQ and CaGI scales were debriefed using a 'think aloud' technique whereby caregivers were asked to read each question or instruction out loud and then vocalise their thoughts as they read and as they selected their responses. Non-leading, open-ended interview questions (e.g. "How would you describe this question in your own words?") were used to ensure that all items were explored thoroughly. Probes were used where necessary, specifically to establish the caregiver's understanding and interpretation of questions and instructions (e.g. "What does feeling 
Fig. 1 Caregiver Global Impression (CaGI) scales

\section{Caregiver Global Impression (CaGl)}

Please answer the following questions which ask about your experiences of caring for a person with schizophrenia.

\section{Severity of symptoms}

Please rate the severity of his/her symptoms during the past 4 weeks.

\begin{tabular}{|c|c|c|c|c|c|}
\hline No symptoms & $\begin{array}{c}\text { Very mild } \\
\text { symptoms }\end{array}$ & $\begin{array}{c}\text { Mild } \\
\text { symptoms }\end{array}$ & $\begin{array}{c}\text { Moderate } \\
\text { symptoms }\end{array}$ & $\begin{array}{c}\text { Severe } \\
\text { symptoms }\end{array}$ & $\begin{array}{c}\text { Very severe } \\
\text { symptoms }\end{array}$ \\
\hline$\square$ & 2 & 3 & 4 & 5 & 6 \\
$\square$ & $\square$ & $\square$ & $\square$ & $\square$ & $\square$ \\
\hline
\end{tabular}

\section{Degree of change in symptoms}

Overall, how have his/her symptoms changed (if at all) since the beginning of the study (before starting treatment)?

\begin{tabular}{|c|c|c|c|c|c|c|}
\hline $\begin{array}{c}\text { Very much } \\
\text { improved } \\
\text { since } \\
\text { treatment } \\
\text { started } \\
1\end{array}$ & $\begin{array}{c}\text { Much } \\
\text { improved }\end{array}$ & $\begin{array}{c}\text { Minimally } \\
\text { improved }\end{array}$ & $\begin{array}{c}\text { No change } \\
\text { since } \\
\text { treatment } \\
\text { started }\end{array}$ & $\begin{array}{c}\text { Minimally } \\
\text { worse }\end{array}$ & $\begin{array}{c}\text { Much } \\
\text { worse }\end{array}$ & $\begin{array}{c}\text { Very much } \\
\text { worse } \\
\text { since } \\
\text { treatment } \\
\text { started }\end{array}$ \\
$\square$ & 2 & 3 & 4 & 5 & 6 & 7 \\
\hline
\end{tabular}

\section{Degree of change in experiences of caring}

Overall, how much have your experiences of caring for a person with schizophrenia changed (if at all) since the beginning of the study (before the person started treatment)?

\begin{tabular}{|c|c|c|c|c|c|c|}
\hline $\begin{array}{c}\text { Very much } \\
\text { improved } \\
\text { since } \\
\text { treatment } \\
\text { started }\end{array}$ & $\begin{array}{c}\text { Much } \\
\text { improved }\end{array}$ & $\begin{array}{c}\text { Minimally } \\
\text { improved }\end{array}$ & $\begin{array}{c}\text { No change } \\
\text { since } \\
\text { treatment } \\
\text { started }\end{array}$ & $\begin{array}{c}\text { Minimally } \\
\text { worse }\end{array}$ & $\begin{array}{c}\text { Much } \\
\text { worse }\end{array}$ & $\begin{array}{c}\text { Very much } \\
\text { worse } \\
\text { since } \\
\text { treatment } \\
\text { started }\end{array}$ \\
\hline$\square$ & 2 & 3 & 4 & 5 & 6 & 7 \\
\hline$\square$ & $\square$ & $\square$ & $\square$ & $\square$ & $\square$ \\
\hline
\end{tabular}

'angry' mean to you? How is that different to feeling 'frustrated?").

\subsubsection{Ethical Considerations}

The study was conducted in accordance with the Declaration of Helsinki and was approved by Copernicus Group, a centralized Institutional Review Board (IRB) in the USA (IRB number: ADE2-12-035). Study procedures ensured that written informed consent was obtained from both people with schizophrenia and their caregivers prior to the collection of any data.

\subsubsection{Qualitative Analysis of Interview Transcripts}

Qualitative analysis during 'cognitive debriefing' focused specifically on whether SCQ and CaGI concepts and questions were relevant and consistently understood by participants. A qualitative software package (Atlas.ti; ATLAS.ti Scientific Software Development GmbH, Berlin, 
Germany) [86] was used to facilitate the coding and analysis of verbatim interview transcripts using methods derived from thematic analysis [87, 88]. Each transcript was assessed and patient comments that pertained to the main research questions were highlighted. After analysing each transcript, the coded statements were then moved into their relevant domains. A list of patient statements was generated for each domain and analysed accordingly.

\section{Results}

3.1 Review of the ZBI and Initial Modification to Form the SCQ

\subsubsection{Review of the Literature Relating to Development and Validation of the ZBI}

Consideration of existing literature summarising the development, validation and use of the ZBI as well as a review of the face validity of the ZBI by the authors highlighted a number of issues that might compromise the validity and sensitivity of the ZBI for use as a self-report questionnaire in clinical research in schizophrenia. As a result, the following operational changes were implemented to the questionnaire:

- Although the term 'burden' was appropriate for the ZBI (developed to be administered by interview), use of 'burden' in the title of a self-report questionnaire to be completed by caregivers may increase the likelihood of socially desirable answers that underestimate the magnitude of impact experienced. This could potentially manifest as floor effects on such questions (i.e. patients indicating 'no impact'). The modified version of the $\mathrm{ZBI}$ for use in schizophrenia caregivers is therefore referred to as the SCQ.

- Questions 4, 5, 6, 13 and 17 were reworded to focus on the impact of the person's schizophrenia or their behaviour and not the person with schizophrenia themselves, minimising the potential impact of social desirability bias.

- The original ZBI does not include a recall period, which makes it difficult to determine how long respondents are thinking back to when selecting their answers. This is of particular concern for questionnaires implemented in a clinical trial and where differences are to be assessed over time, and, consequently, may reduce sensitivity of the questionnaire. As such, a recall period of the "past four weeks" was implemented throughout the SCQ. Four weeks was specifically chosen to minimise recall bias by keeping the recall period short, while limiting responder burden by minimising the potential frequency of assessment.

- ZBI questions make reference to caring for a relative, as it was intended that the interviewer would replace this word with the appropriate term (e.g. mother, son). In appreciation that the SCQ could be completed by non-family members who may provide care and support for people with schizophrenia, the questions were amended to no longer make reference to the relationship between care provider and care recipient.

- All questions in the ZBI ask respondents to "reflect how they sometimes feel when taking care of another person" and instruct "After each statement, indicate how often you feel that way". Frequency measures are most appropriate for observable behaviours where an event is experienced or not. Emotional evaluations and attitudes, however, may be better understood in terms of magnitude or strength of feeling. SCQ items pertaining to the experience of emotions are therefore measured in terms of magnitude or strength of feeling where appropriate, while items measuring behaviour are measured in terms of frequency.

- Item 9 was deleted due to the presence of ambiguous wording ("strained"). Items measuring stress, tiredness and worry have been added to the SCQ and are intended to capture this concept.

- Finally, concerns emerged that a 5-point Likert-type response scale in the ZBI may be less sensitive to changes in the impact of caring for a person with schizophrenia given the extent of difference between adjacent response categories. Response options for all questions were therefore amended to an 11-point numerical rating scale (NRS) in the SCQ to provide greater opportunity for change (albeit only subtle changes) over time.

\subsubsection{Review of the Qualitative Literature}

Nineteen qualitative research articles were also reviewed to identify issues of importance to caregivers of people with schizophrenia [21-27, 29-44, 89]. Findings supported the relevance of many concepts assessed by the ZBI for caregivers of people with schizophrenia (Table 3). Review of this research also highlighted some concepts considered important to caregivers of people with schizophrenia that were not assessed by the original ZBI. As such, nine additional questions assessing these concepts were added to the SCQ for cognitive testing among schizophrenia caregivers (SCQ questions 6, 23-30) (Table 3). 


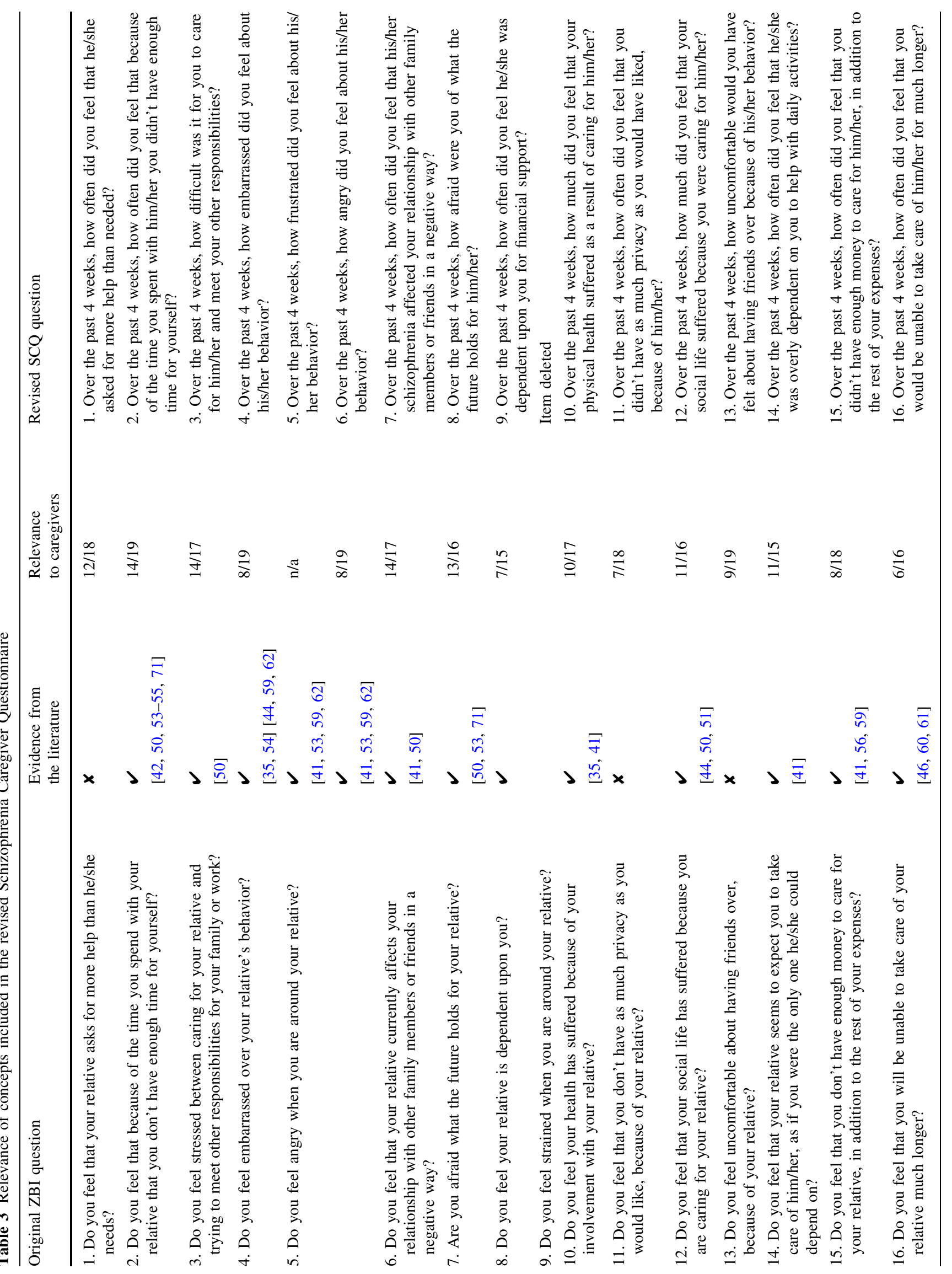




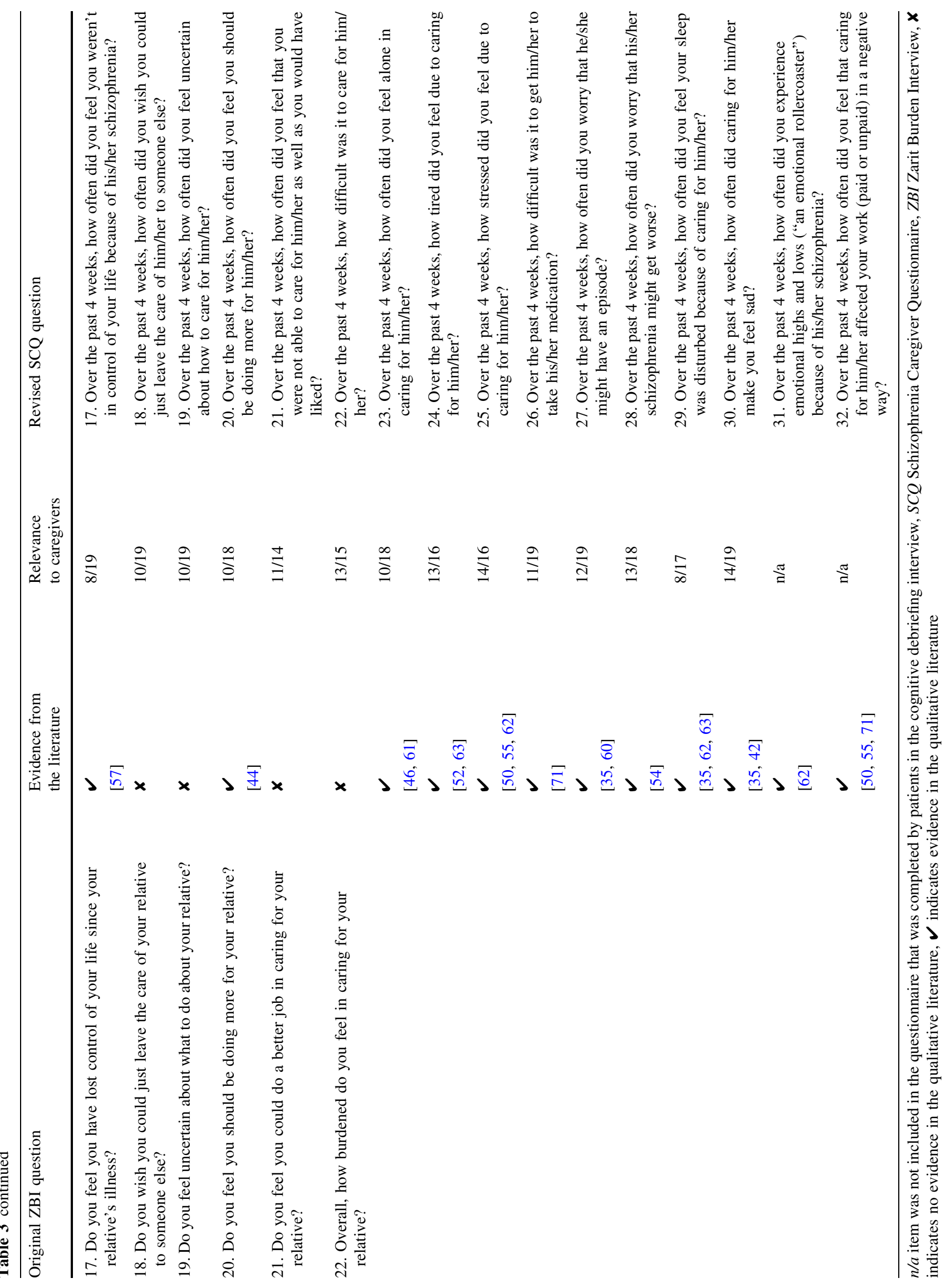


Table 4 Demographic characteristics for persons with schizophrenia $(n=19)$

\begin{tabular}{|c|c|}
\hline Demographic characteristic & $\begin{array}{l}\text { Persons with } \\
\text { schizophrenia }\end{array}$ \\
\hline Age (years) [mean (range)] & $51.84(21-82)$ \\
\hline \multicolumn{2}{|l|}{$\operatorname{Sex}(n)$} \\
\hline Male & 7 \\
\hline Female & 12 \\
\hline \multicolumn{2}{|l|}{ Ethnicity $(n)$} \\
\hline Black/African American & 12 \\
\hline $\begin{array}{l}\text { Hispanic/Spanish American/Latin } \\
\text { (of any race) }\end{array}$ & 1 \\
\hline White/Caucasian & 6 \\
\hline Years since diagnosis [mean (range)] & $16(3-42)$ \\
\hline \multicolumn{2}{|l|}{ Schizophrenia subtype $(n)$} \\
\hline Paranoid & 10 \\
\hline Disorganized & 4 \\
\hline Undifferentiated & 2 \\
\hline Catatonic & 2 \\
\hline Paranoid, disorganized & 1 \\
\hline \multicolumn{2}{|l|}{ Schizophrenia severity $(n)$} \\
\hline CGI-S score 4 & 9 \\
\hline CGI-S score 5 & 5 \\
\hline CGI-S score 6 & 5 \\
\hline \multicolumn{2}{|l|}{ Medication $(n)$} \\
\hline Typical antipsychotics & 6 \\
\hline Haloperidol & 5 \\
\hline Chlorpromazine & 3 \\
\hline Atypical antipsychotics & 11 \\
\hline Abilify ${ }^{\circledR}$ & 4 \\
\hline Risperdal $^{\circledR}$ & 5 \\
\hline Zyprexa $^{\circledR}$ & 3 \\
\hline Seroquel $^{\circledR}$ & 0 \\
\hline Symbyax $^{\circledR}$ & 1 \\
\hline Geodon $^{\mathrm{TM}}$ & 2 \\
\hline Other & 6 \\
\hline $\begin{array}{l}\text { People with schizophrenia taking both typical and } \\
\text { atypical treatments }\end{array}$ & 5 \\
\hline
\end{tabular}

CGI-S Clinical Global Impression-Severity scale

\subsection{Cognitive Debriefing of the SCQ}

\subsubsection{Demographic Characteristics}

A diverse sample of 19 caregivers of people with schizophrenia was recruited who cared for a diverse sample of people with schizophrenia (Tables 4, 5). The average age of caregivers was 51.6 years and the caregiver sample was predominantly female (79\%), which is consistent with previous research in samples of caregivers of people with schizophrenia [34, 90]. Caregivers were related to the person with schizophrenia in a number of ways, including parent, sibling, spouse or child, and the majority $(n=15)$ lived with the person with schizophrenia. Most of the caregivers worked and caregivers had a range of educational statuses. On average, caregivers had been caring for the person with schizophrenia for 10 years (range $1-32$ years) and more than half $(n=11)$ spent over $40 \mathrm{~h} \mathrm{a}$ week caring for the person.

People with schizophrenia had an average age of 52 (range 21-82) years and were also predominantly female (12/19). On average, they had been diagnosed with schizophrenia for 16 (range 3-42) years and they represented five DSM-IV-TR subtypes [91] and had a range of severities of schizophrenia as rated by the CGI.

\subsubsection{Cognitive Debriefing Findings}

Feedback from participants indicated that completing the SCQ was "easy" and "straightforward" with few difficulties encountered during completion. Feedback also supported the initial modifications made to the questionnaire following the literature review. The newly specified 4-week recall period for all SCQ questions, for example, was universally understood by participants, and when asked to explain their answers to SCQ questions participants consistently referred to their experiences in the past 4 weeks.

\section{"I was thinking over the last month". (101-F-58-U)}

Similarly, feedback from participants indicated that the 0-10 NRS used in the SCQ was well understood and was an intuitive means of reporting the impact of caring for a person with schizophrenia:

"None of the time, all the time, half of the time-I'm going to give it a seven. A little more than half of the time. That's how I'm splitting it up" (211-F-59-D)

Furthermore, despite the small sample $(n=19)$, the caregivers interviewed as part of this study provided responses for the majority of SCQ items that were distributed across the entire response continuum, providing preliminary support for the validity of the $0-10$ NRS response scale in this population (Fig. 2).

Feedback from the cognitive debriefing interviews indicated that all items were well-understood and consistently interpreted by caregivers as referring to impacts due to their role as a caregiver. No participants reported discomfort in answering any of the SCQ items or feeling that items were putting blame on patients in any way.

While SCQ questions were generally considered by participants to be well-worded and few difficulties in understanding of the questions were evident, some caregivers proposed valid suggestions of ways in which question wording could be modified to further improve understanding 
Table 5 Caregiver demographic characteristics $(n=19)$

\begin{tabular}{|c|c|}
\hline Demographic characteristic & Caregivers \\
\hline Age (years) [mean (range)] & $51.63(28-69)$ \\
\hline \multicolumn{2}{|l|}{$\operatorname{Sex}(n)$} \\
\hline Male & 4 \\
\hline Female & 15 \\
\hline \multicolumn{2}{|l|}{ Ethnicity $(n)$} \\
\hline Black/African American & 11 \\
\hline Hispanic/Spanish American/Latin (of any race) & 2 \\
\hline White/Caucasian & 6 \\
\hline \multicolumn{2}{|l|}{ Relationship to person with schizophrenia $(n)$} \\
\hline Parent & 6 \\
\hline Partner/spouse & 2 \\
\hline Sibling & 6 \\
\hline Son/daughter & 3 \\
\hline Other & 2 \\
\hline \multicolumn{2}{|l|}{ Sex match $(n)$} \\
\hline \multicolumn{2}{|l|}{ Yes } \\
\hline Female & 10 \\
\hline Male & 2 \\
\hline No & 7 \\
\hline \multicolumn{2}{|l|}{ Education $(n)$} \\
\hline High school diploma & 7 \\
\hline College or university degree & 5 \\
\hline Graduate or professional degree & 5 \\
\hline Some years of college & 2 \\
\hline \multicolumn{2}{|l|}{ Work status $(n)$} \\
\hline Working full- or part-time & 12 \\
\hline Full time homemaker & 3 \\
\hline Not working & 1 \\
\hline Retired & 2 \\
\hline Other & 1 \\
\hline \multicolumn{2}{|l|}{ Co-residence $(n)$} \\
\hline Yes & 15 \\
\hline No & 4 \\
\hline $\begin{array}{l}\text { Years spent caring for person with schizophrenia } \\
\text { [mean (range)] }\end{array}$ & $10.24(1-32)$ \\
\hline \multicolumn{2}{|c|}{ Hours per week spent caring for person with schizophrenia $(n)$} \\
\hline$<20$ & 1 \\
\hline $21-40$ & 7 \\
\hline $40+$ & 11 \\
\hline Range & $14-168$ \\
\hline Mean & 86.33 \\
\hline
\end{tabular}

and relevance. One such change included rewording question 27 from "worry that he/she might have an episode of disturbing or violent behaviour?" to "worry that he/she might have an episode?" to make it more relevant to behaviours present in all subtypes of schizophrenia.

Caregiver feedback indicated that the SCQ provided a comprehensive assessment of the issues that may affect caregivers of people with schizophrenia. On the basis of caregiver feedback, however, three additional questions were added to the SCQ. These questions aimed to assess caregivers' frustration at the person with schizophrenia's behaviour, caregivers' experience of emotional highs and lows, and the impact of caring for a person with schizophrenia on caregivers' ability to complete paid or unpaid work.

"There's times I've yelled at my mother when I've gotten frustrated. So I've-of course I feel guilty of that and the guilt causes stress". (103-F-38-P)

“Emotionally, it's a rollercoaster”. (318-M-55-P)

"So I gave up my business basically so I could be home more-uh, to take care of him." (109-F-69-P).

Feedback from caregivers interviewed as part of this study also supported the validity of the CaGI scales, with these newly developed scales being readily understood by caregivers who provided responses across the whole response continuum.

"That's a good question... You have very mild, mild... Because there can be so many degrees of it". (104-F-48-D).

\section{Discussion}

A survey by Rethink Mental Illness in 2003 showed that $90 \%$ of caregivers are adversely affected by the caring role in terms of leisure activities, career progress, financial circumstances and family relationships, and $41 \%$ have significant or moderately reduced mental and physical health [9]. A review of existing qualitative research and insights from qualitative interviews outlined in this manuscript reinforce the impact that caring for a person with schizophrenia has on caregivers and confirms findings from prior qualitative research conducted by the authors [6].

Assessment of caregiver burden in both clinical trials and clinical practice could improve awareness, tracking and management of impact on caregivers, thus providing opportunity for increased support. In turn, this could reduce the substantial direct and indirect costs associated with caregiver healthcare needs, loss of productivity and reliance on formal caregivers. This is of increasing importance to healthcare decision makers such as the National Institute for Health and Care Excellence (NICE), who highlighted the need for caregiver support in their latest guidance on schizophrenia management [92].

The ZBI is a well-validated and widely used instrument for measuring caregiver burden in caregivers of patients 
Fig. 2 Example response distributions for SCQ item
Over the past four weeks, how stressed did you feel due to caring for him/her?

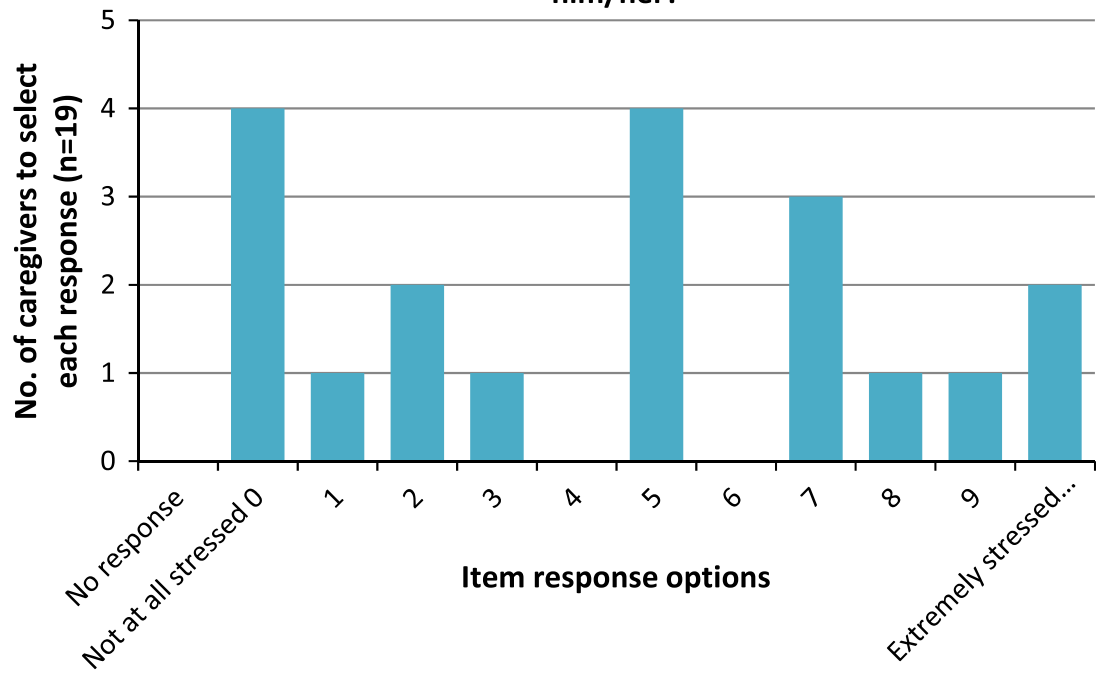

with Alzheimer's disease. The SCQ was adapted from the ZBI in accordance with best practice recommendations for the development and modification of self-report questionnaires $[20,60]$ to provide a disease-specific means of assessing the impact of caring for a person with schizophrenia. It addresses many of the limitations of the ZBI (e.g. lack of specified recall period, limited response continuum), making it more appropriate for use as an assessment in clinical trials and non-interventional observational studies. There is also potential for the SCQ to be used to support clinical practice, where it may help to identify cases where additional support from healthcare professionals and/or social care services is needed to minimise impact on caregivers' physical/psychological health and their ability to provide informal care to the person with schizophrenia.

Although our findings provided strong support for the face and content validity of the SCQ, it is recognised that further evidence from quantitative studies in informal caregivers of people with schizophrenia is needed to confirm the validity of the SCQ and the CaGI scales. Prior research has supported the psychometric validity of the ZBI (although there is only limited evidence specific to schizophrenia) [11-15, 19, 46, 51-53]. Further exploration of the content validity of the SCQ using item-response theories are therefore planned to help ensure adequate targeting of the SCQ to the caregivers of people with schizophrenia (e.g. absence of gaps in measurement and clusters of questions) and (combined with traditional psychometric analyses) will be used to inform questionnaire domain structure and questionnaire scoring. Sensitivity of the questionnaire to changes in caregiver burden and definition of minimal important differences will then be explored during interventional studies.
It is noted that initial research was only conducted in the USA with US English-speaking caregivers; a conceivable limitation of the questionnaire, therefore, being that it may not be culturally or linguistically relevant in other countries. To facilitate use of the SCQ in other languages and cultures, work is currently ongoing to translate and linguistically validate the SCQ for use in other countries using industry gold-standard techniques. Future research may also look to investigate the impact of caring for a person with predominantly negative symptoms (such as being emotionless or withdrawn) versus the impact of caring for a person with predominantly positive symptoms (such as hallucinations or delusions) as research suggests that issues for caregivers of such patients may be different.

\section{Conclusions}

The newly developed SCQ is a disease-specific questionnaire for assessing the impact of providing informal care to a person with schizophrenia. The questionnaire has demonstrated strong face and content validity but further research is needed to establish the psychometric validity of the scale. Nonetheless, the SCQ represents a promising tool for use in clinical research and clinical practice.

Acknowledgments The authors would like to thank the caregivers of people with schizophrenia who participated in the qualitative interviews. The authors would also like to thank Caroline Anfray and the Mapi Research Trust for facilitating copyright and permissions for use of the SCQ. This project was funded by F. Hoffmann-La Roche Ltd who commissioned Adelphi Values, a health outcomes agency. AG, LA, CM and CT have no other competing interests to declare. DR and CB are both employees of F. Hoffmann-La Roche Ltd. SZ is a faculty member at Penn State University. He receives royalties for the SCQ and has no other competing interests. 
Author contributions $\mathrm{DR}$ and $\mathrm{CB}$ conceived the study. DR, CB, $\mathrm{AG}$, and LA designed the research and provided scientific oversight and review throughout the research process. CT and CM performed the literature review, conducted the interviews and the primary data analysis. All authors were all involved in the interpretation of research findings and developed the manuscript.

Intellectual property The Schizophrenia Caregiver Questionnaire (SCQ) and the Caregiver Global Impression Scales (CaGI), including but not limited to all and any translations and other derivatives (e.g. electronic versions) are protected by international copyright: SCQ $~()$, CaGI (c) F. Hoffmann-La Roche Ltd \& Professor Zarit 2012. For information on, or permission to use, the SCQ or CaGI, please contact the Mapi Research Trust. E-mail: PRO-information@mapi-trust.org; website: http://www.proqolid.org.

Open Access This article is distributed under the terms of the Creative Commons Attribution Noncommercial License which permits any noncommercial use, distribution, and reproduction in any medium, provided the original author(s) and the source are credited.

\section{References}

1. Rossler W, Salize HJ, Cucchiaro G, Reinhard I, Kernig C. Does the place of treatment influence the quality of life of schizophrenics? Acta Psychiatr Scand. 1999;100(2):142-8.

2. Honkonen T, Saarinen S, Salokangas RK. Deinstitutionalization and schizophrenia in Finland II: discharged patients and their psychosocial functioning. Schizophr Bull. 1999;25(3):543-51.

3. Nevada Revised Statutes (NRS) 453A.080, 2012. Caregiver law \& legal definition. http://definitions.uslegal.com/c/caregiver/. Accessed 20 Jan 2015.

4. Arno PS, Levine C, Memmott MM. The economic value of informal caregiving. Health Aff. 1999;18(2):182-8.

5. Awad AG, Voruganti LN. The burden of schizophrenia on caregivers: a review. Pharmacoeconomics. 2008;26(2):149-62.

6. Gater A, Rofail D, Tolley C, Marshall C, Abetz L, Zarit SH, et al. "Sometimes it's difficult to have a normal life": Results from a qualitative study exploring caregiver burden in schizophrenia. Schizophr Res Treat. 2014;2014:368215.

7. Hoenig J, Hamilton MW. The schizophrenia patient in the community and his effect on the household. Int J Soc Psychiatry. 1966;12:165-76.

8. Dillehay RC, Sandys MR. Caregivers for Alzheimer's patients: what we are learning from research. Int J Aging Hum Dev. 1990;30(4):263-85.

9. Andrews A, Knapp M, McCrone P, Parsonage M, Trachtenberg M. Effective interventions in schizophrenia: the economic case. A report prepared for the Schizophrenia Commission. London: Rethink Mental illness; 2012. http://www.lse.ac.uk/LSEH ealthAndSocialCare/pdf/LSE-economic-report-FINAL-12-Nov. pdf. Accessed 18 Oct 2013.

10. Zarit SH, Reever KE, Bach-Peterson J. Relatives of the impaired elderly: correlates of feelings of burden. Gerontologist. 1980;20(6):649-55.

11. Arai Y, Kudo K, Hosokawa T, Washio M, Miura H, Hisamichi S. Reliability and validity of the Japanese version of the Zarit Caregiver Burden interview. Psychiatry Clin Neurosci. 1997;51(5):281-7.

12. Braun M, Scholz U, Hornung R, Martin M. The burden of spousal caregiving: a preliminary psychometric evaluation of the German version of the Zarit burden interview. Aging Ment Health. 2010;14(2):159-67.
13. Chan TSF, Lam LCW, Chiu HFK. Validation of the Chinese Version of the Zarit Burden Interview. Hong Kong J Psychiatry. 2005;15:9-13.

14. Chattat R, Cortesi V, Izzicupo F, Del Re ML, Sgarbi C, Fabbo $\mathrm{A}$, et al. The Italian version of the Zarit Burden Interview; a validation study. Int Psychogeriatr. 2011;23(5):797805.

15. Martin-Carrasco M, Otermin P, Perez-Camo V, Pujol J, Aguera L, Martin MJ, et al. EDUCA study: psychometric properties of the Spanish version of the Zarit Caregiver Burden Scale. Aging Ment Health. 2010;14(6):705-11.

16. Yoon E, Robinson M. Psychometric properties of the Korean version of the Zarib Burden Interview (K-ZBI): preliminary analyses. J Soc Work Res Eval. 2005;6(1):75-85.

17. Caqueo-Urizar A, Gutierrez-Maldonado J. Burden of care in families of patients with schizophrenia. Qual Life Res. 2006;15(4):719-24.

18. Gutierrez-Maldonado J, Caqueo-Urizar A. Effectiveness of a psycho-educational intervention for reducing burden in Latin American families of patients with schizophrenia. Qual Life Res. 2007;16(5):739-47.

19. Hebert R, Bravo G, Preville M. Reliability, validity and reference values of the Zarit Burden Interview for assessing informal caregivers of community-dwelling older persons with dementia. Can J Aging. 2000;19(4):494-507.

20. FDA. Guidance for industry. Patient-reported outcomes measures: use in medical product development to support labeling claims. Silver Spring: FDA; 2009.

21. Jungbauer J, Wittmund B, Dietrich S, Angermeyer MC. The disregarded caregivers: subjective burden in spouses of schizophrenia patients. Schizophr Bull. 2004;30:665-75.

22. Gerace LM, Camilleri D, Ayres L. Sibling perspectives on schizophrenia and the family. Schizophr Bull. 1993;19:637-47.

23. Winefield HR, Harvey EJ. Needs of family caregivers in chronic schizophrenia. Schizophr Bull. 1994;20:557-66.

24. Stalberg G, Ekerwald H, Hultman CM. At issue: siblings of patients with schizophrenia: sibling bond, coping patterns, and fear of possible schizophrenia heredity. Schizophr Bull. 2004;30:445-58

25. Chen FP, Greenberg JS. A positive aspect of caregiving: the influence of social support on caregiving gains for family members of relatives with schizophrenia. Community Ment Health J. 2004;40:423-35.

26. Stein $\mathrm{CH}$, Wemmerus VA. Searching for a normal life: personal accounts of adults with schizophrenia, their parents and wellsiblings. Am J Community Psychol. 2001;29:725-46.

27. Jungbauer J, Stelling $\mathrm{K}$, Dietrich $\mathrm{S}$, Angermeyer MC. Schizophrenia: problems of separation in families. J Adv Nurs. 2004;47:605-13.

28. Chaffey L, Fossey E. Caring and daily life: occupational experiences of women living with sons diagnosed with schizophrenia. Aust Occup Ther J. 2004;51:199-207.

29. Coldwell J, Meddings S, Camic PM. How people with psychosis positively contribute to their family: a grounded theory analysis. J Fam Ther. 2011;33:353-71.

30. Friedrich RM, Lively S, Rubenstein L, Buckwalter K. The friedrich-lively instrument to assess the impact of schizophrenia on siblings (FLIISS): part I-instrument construction. J Nurs Meas. 2002;10:219-30.

31. Birchwood M, Cochrane R. Families coping with schizophrenia: coping styles, their origins and correlates. Psychol Med. 1990;20:857-65.

32. Ryan KA. Mothers of adult children with schizophrenia: an ethnographic study. Schizophr Res. 1993;11:21-31.

33. Chesla CA. Parents' caring practices with schizophrenic offspring. Qual Health Res. 1991;1:446-68. 
34. Jungbauer J, Wittmund B, Dietrich S, Angermeyer MC. Subjective burden over 12 months in parents of patients with schizophrenia. Arch Psychiatr Nurs. 2003;17:126-34.

35. Bogren LY. Expressed emotion, family burden, and quality of life in parents with schizophrenic children. Nordic J Psychiatry. 1997;51:229-33.

36. Howard PB. The experience of fathers of adult children with schizophrenia. Issues Ment Health Nurs. 1998;19:399-413.

37. Wancata J, Krautgartner M, Berner J, Scumaci S, Freidl M, Alexandrowicz R, et al. The "Carers' needs assessment for Schizophrenia". An instrument to assess the needs of relatives caring for schizophrenia patients. Soc Psychiatry Psychiatr Epidemiol. 2006;41:221-9.

38. Jungbauer J, Angermeyer MC. Living with a schizophrenic patient: a comparative study of burden as it affects parents and spouses. Psychiatry. 2002;65:110-23.

39. Rudge T, Morse K. Did anything change? Caregivers and schizophrenia after medication changes. J Psychiatr Ment Health Nurs. 2004;11:3-11.

40. Macinnes DL, Watson JP. The differences in perceived burdens between forensic and non-forensic caregivers of individuals suffering from schizophrenia. J Ment Health. 2002;11:375-88.

41. Schmid R, Schielein T, Binder H, Hajak G, Spiessl H. The forgotten caregivers: Siblings of schizophrenic patients. Int J Psychiatry Clin Pract. 2009;13:326-37.

42. Tuck I, du MP, Evans G, Shupe J. The experience of caring for an adult child with schizophrenia. Arch Psychiatr Nurs. 1997;11:118-25.

43. Milliken PJ. Disenfranchised mothers: caring for an adult child with schizophrenia. Health Care Women Int. 2001;22:149-66.

44. Potasznik H, Nelson G. Stress and social support: the burden experienced by the family of a mentally ill person. Am J Community Psychol. 1984;12:589-607.

45. Bachner YG, O'Rourke N. Reliability generalization of responses by care providers to the Zarit Burden Interview. Aging Ment Health. 2007;11(6):678-85.

46. Ko KT, Yip PK, Liu SI, Huang CR. Chinese version of the Zarit caregiver Burden Interview: a validation study. Am J Geriatr Psychiatry. 2008;16(6):513-8.

47. Lai DWL. Validation of the Zarit Burden Interview for Chinese Canadian caregivers. Social Work Res. 2007;31(1):45-53.

48. Lu L, Wang L, Yang X, Feng Q. Zarit Caregiver Burden Interview: development, reliability and validity of the Chinese version. Psychiatry Clin Neurosci. 2009;63(6):730-4.

49. Marquez JA, Garcia JIR. Family caregivers' monitoring of medication usage: a qualitative study of Mexican-origin families with serious mental illness. Cult Med Psychiatry. 2011;35:63-82.

50. Schreiner AS, Morimoto T, Arai Y, Zarit S. Assessing family caregiver's mental health using a statistically derived cut-off score for the Zarit Burden Interview. Aging Ment Health. 2006;10(2):107-11.

51. Seng BK, Luo N, Ng WY, Lim J, Chionh HL, Goh J, et al. Validity and reliability of the Zarit Burden Interview in assessing caregiving burden. Ann Acad Med Singap. 2010;39(10):758-63.

52. Taub A, Andreoli SB, Bertolucci PH. Dementia caregiver burden: reliability of the Brazilian version of the Zarit caregiver burden interview. Cad Saude Publica. 2004;20(2):372-6.

53. Wang G, Cheng Q, Wang Y, Deng YL, Ren RJ, Xu W, et al. The metric properties of Zarit caregiver burden scale: validation study of a Chinese version. Alzheimer Dis Assoc Disord. 2008;22(4):321-6.

54. Gutierrez-Maldonado J, Caqueo-Urizar A, Kavanagh DJ. Burden of care and general health in families of patients with schizophrenia. Soc Psychiatry Psychiatr Epidemiol. 2005;40(11):899-904
55. Garcia JIR, Hernadez B, Dorian M. Mexican American caregivers' coping efficacy: associations with caregivers' distress and positivity to their relatives with schizophrenia. Soc Psychiatry Psychiatr Epidemiol. 2009;44:162-70.

56. Hanzawa S, Bae JK, Tanaka H, Bae YJ, Tanaka G, Inadomi H, et al. Caregiver burden and coping strategies for patients with schizophrenia: comparison between Japan and Korea. Psychiatry Clin Neurosci. 2010;64(4):377-86.

57. Hanzawa S, Tanaka G, Inadomi H, Urata M, Ohta Y. Burden and coping strategies in mothers of patients with schizophrenia in Japan. Psychiatry Clin Neurosci. 2008;62(3):256-63.

58. Kaufman AV, Scogin F, Macneil G, Leeper J, Wimberly J. Helping aging parents of adult children with serious mental illness. J Soc Serv Res. 2010;36(5):445-59.

59. Magana SM, Ramirez Garcia JI, Hernandez MG, Cortez R. Psychological distress among Latino family caregivers of adults with schizophrenia: the roles of burden and stigma. Psychiatr Serv. 2007;58:378-84.

60. EMA. Reflection paper on the regulatory guidance for the use of health-related quality of life (HRQL) measures in the evaluation of medicinal products. London: European Medicines Agency; 2005.

61. Medin J, Arbuckle R, Abetz L, Halling K, Kulich K, Edvardsson $\mathrm{N}$, et al. Development and validation of the AFSymp: an atrial fibrillation-specific measure of patient-reported symptoms. Patient. 2014;7(3):319-27.

62. Bonner N, Abetz L, Meunier J, Sikirica M, Mathai SC. Development and validation of the living with pulmonary hypertension questionnaire in pulmonary arterial hypertension patients. Health Qual Life Outcomes. 2013;11:161.

63. Arbuckle R, Abetz L, Durmer JS, Ivanenko A, Owens JA, Croenlein J, et al. Development of the Pediatric Restless Legs Syndrome Severity Scale (P-RLS-SS): a patient-reported outcome measure of pediatric RLS symptoms and impact. Sleep Med. 2010;11(9):897-906.

64. Arbuckle R, Atkinson MJ, Clark M, Abetz L, Lohs J, Kuhagen I, et al. Patient experiences with oily skin: the qualitative development of content for two new patient reported outcome questionnaires. Health Qual Life Outcomes. 2008;6:80.

65. Rofail D, Abetz L, Viala M, Gait C, Baladi JF, Payne K. Satisfaction and adherence in patients with iron overload receiving iron chelation therapy as assessed by a newly developed patient instrument. Value Health. 2009;12(1):109-17.

66. Cappelleri JC, Gerber RA, Quattrin T, Deutschmann R, Luo X, Arbuckle R, et al. Development and validation of the WEll-being and Satisfaction of CAREgivers of Children with Diabetes Questionnaire (WE-CARE). Health Qual Life Outcomes. 2008;6:3.

67. Rofail D, Gray R, Gournay K. The development and internal consistency of the satisfaction with Antipsychotic Medication Scale. Psychol Med. 2005;35(7):1063-72.

68. Clerson P, Graesslin O, Gater A, Taylor F, Filonenko A, Schellschmidt I, et al. EVAPIL-R Scale: continuous development and validation of a tool to assess patient-reported tolerability of different contraceptive methods in longitudinal studies. Clin Ther. 2014;36(5):638-47.

69. Morcarski M, Gater A, Fleming S, Nelsen LM, Coons SJ. Development of the initial version of the Asthma Daily Symptom Diary (ADSD) [abstract]. In: American Thoracic Society International Conference Abstracts. A33. CLINICAL ASTHMA I. Am J Respir Crit Care Med. 2014;189 (Meeting Abstracts): A1347.

70. Gater A, Wichmann K, Seitz C, Gerlinger C, Taylor F, Chen WH, et al. Assessing the content validity of the endometriosis symptom diary and endometriosis impact scale. Value Health. 2014;17(3):A198-9. 
71. Hamilton M, Scale HA, Guy W. ECDEU assessment manual for psychopharmacology. Rockville: National Institute of Mental Health; 1976.

72. Patrick DL, Burke LB, Gwaltney CJ, Leidy NK, Martin ML, Molsen E, et al. Content validity-establishing and reporting the evidence in newly-developed patient-reported outcomes (PRO) instruments for medical product evaluation: ISPOR PRO Good Research Practices Task Force report: part 2-assessing respondent understanding. Value Health. 2011;14(8):978-88.

73. Francis JJ, Johnston M, Robertson C, Glidewell L, Entwistle V, Eccles MP, et al. What is an adequate sample size? Operationalising data saturation for theory-based interview studies. Psychol Health. 2010;25(10):1229-45.

74. Guest G, Bunce A, Johnson L. How many interviews are enough? An experiment with data saturation and variability. Field Methods. 2006;18:59-82.

75. Kimhy D, Harlap S, Fennig S, Deutsch L, Draiman BG, Corcoran $\mathrm{C}$, et al. Maternal household crowding during pregnancy and the offspring's risk of schizophrenia. Schizophr Res. 2006;86:23-9.

76. Magliano L, Fiorillo A, Malangone C, Aletti A, Belotti G, Bevilacqua $\mathrm{P}$, et al. Family burden in schizophrenia: effects of socio-environmental and clinical variables and family intervention [in Italian]. Epidemiol Psichiatr Soc. 1998;7(03):178-87.

77. Dyck DG, Short R. Vitaliano PP. Predictors of burden and infectious illness in schizophrenia caregivers. Psychosom Med. 1999;61(4):411-9.

78. Mors O, Sorensen LV, Therkildsen ML. Acta Psychiatr Scand. 1992;85(5):337-44.

79. Wolthaus JED, Dingemans PMAJ, Schene AH, Linszen DH, Wiersma D, Van Den Bosch RJ, et al. Caregiver burden in recentonset schizophrenia and spectrum disorders: the influence of symptoms and personality traits. J Nerv Ment Dis. 2002;190(4):241-7.

80. Provencher HL, Mueser KT. Positive and negative symptom behaviors and caregiver burden in the relatives of persons with schizophrenia. Schizophr Res. 1997;26(1):71-80.

81. Webb C, Pfeiffer M, Mueser KT, Gladis M, Mensch E, DeGirolamo J, et al. Burden and well-being of caregivers for the severely mentally ill: the role of coping style and social support. Schizophr Res. 1998;34(3):169-80.

82. Rosenfarb IS, Bellack AS, Aziz N. A sociocultural stress, appraisal, and coping model of subjective burden and family attitudes toward patients with schizophrenia. J Abnorm Psychol. 2006;115(1):157.

83. Scazufca M, Kuipers E. Links between expressed emotion and burden of care in relatives of patients with schizophrenia. Br J Psychiatry. 1996;168(5):580-7.

84. Li J, Lambert CE, Lambert VA. Predictors of family caregivers' burden and quality of life when providing care for a family member with schizophrenia in the People's Republic of China. Nurs Health Sci. 2007;9(3):192-8.

85. Perlick D, Rosenheck R, Kaczynski R, Swartz M, Lieberman J. Special section on CATIE baseline data: components and correlates of family burden in schizophrenia. Psychiatr Serv. 2006;57(8):1117-25.

86. Atlas.ti software version 7. Berlin: ATLAS.ti Scientific Software Development GmbH; 2013.

87. Joffe H, Yardley L. Content and thematic analysis. In: Marks DF, Yardley L, editors. Research methods for clinical and health psychology. London: Sage Publications; 2004. p. 56-68.

88. Hsieh HF, Shannon SE. Three approaches to qualitative content analysis. Qual Health Res. 2005;15(9):1277-88.

89. Chaffey L, Fossey E. Caring and daily life: Occupational experiences of women living with sons diagnosed with schizophrenia. Aust Occup Therap J. 2004;51:199-207.

90. Roick C, Heider D, Bebbington PE, Angermeyer MC, Azorin JM, Brugha TS, et al. Burden on caregivers of people with schizophrenia: comparison between Germany and Britain. Br J Psychiatry. 2007;190(4):333-8.

91. American Psychiatric Association. Diagnostic and statistical manual of mental disorders. Fourth edition, text revision (DSM-IV-TR). Washington, DC: American Psychiatric Association; 2000.

92. NICE clinical guideline 178. Psychosis and schizophrenia in adults: treatment and management. 2014. http://www.nice.org.uk/ guidance/cg178/resources/guidance-psychosis-and-schizophreniain-adults-treatment-and-management-pdf. Accessed 20 Jan 2015. 